\title{
O DESAFIO DA HUMANIZAÇÃO DOS ALGORITMOS: FORMAÇÕES TECNOLÓGICAS DA SOCIABILIDADE CONTEMPORÂNEA ${ }^{* 1}$
}

\author{
Dalton Lopes Martins
}

Em que pesem todos os momentos em que pude fazer minhas falas aqui, a contribuição que eu queria trazer para esse evento é pensar a humanização dos algoritmos e de que modo tecnologias e sociabilidades estão imbricadas na contemporaneidade.

Eu vou falar umas coisas de início aqui, que podem soar um pouco esotérica para vocês, mas verão que, lá na frente, eu consigo trazer isso para um outro lugar. O que "pegou" quando montamos essa mesa, ao discutir a construção do evento? Quando a gente estava pensando essa coisa das metodologias das ciências de dados, começou a perceber o papel extremamente central que os algoritmos ocupam, hoje, na estruturação dessas tecnologias contemporâneas que passam a ser elementos muito importantes das nossas formas de socialização contemporânea.

Por isso a necessidade de fazermos um pouco dessa discussão das formações tecnológicas e discutir, afinal, onde é que está o elemento humano. Então, a ideia desta mesa é trazer este elemento humano para o papel de centralidade. Vocês verão que ele está num papel de centralidade, sobretudo pelos absurdos que estão acontecendo na contemporaneidade em relação a esses algoritmos.

Vamos fazer um pouco essa viagem, e eu quero começar por um conceito, que é o conceito de computação cognitiva. Falar em "cognitivo", no universo das ciências humanas, provoca reações nem sempre muito fáceis de lidar; ao falar de computação cognitiva, por sua vez, nós estamos falando que os computadores "pensam" e, em certa medida, é isso que a gente está dizendo aqui. É exatamente com isso que eu quero

*DOI- 10.29388/978-65-86678-33-8-0-f.43-66

${ }^{1}$ MARTINS, D. O desafio da humanização dos algorítmos - Dalton Martins. 2018. (1h33m06s). Youtube. Disponível em < https://www.youtube.com/watch?

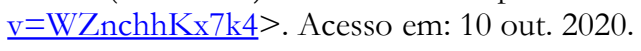


partir: a provocação vem daí.

Há um cenário em que nós temos, a partir da expansão da internet, um grande volume de dados estruturados e não estruturados. $\mathrm{Ou}$ seja, há uma característica do ponto de vista qualitativo que significa que a gente tem à disposição - para todos, em tese - os trabalhos computacionais que vocês puderem imaginar. Uma quantidade de informação que não estava disponível até o início dos anos 2000, ou seja, o que eu tenho de imagem, de áudio, de vídeo digitalizados e disponíveis para circular é uma característica deste tempo.

A ideia de computação cognitiva parte do princípio de que eu tenho amostras muito representativas do que é a produção cultural da contemporaneidade, ou seja, eu tenho de onde partir, essa é a ideia que está por trás.

Surge uma nova classe de problemas para o pessoal da computação e isso do ponto de vista da computação é muito claro: se a gente estivesse discutindo na Ciência da Computação, teria muita tranquilidade para dizer que, a partir da ideia de que eu preciso desenvolver algoritmos para lidar com dados não estruturados, e aqui abro um parêntese para entendermos o que são dados não estruturados.

Um vídeo: toda a informação que compõe um vídeo não está segmentada, ou seja: quem são as pessoas que aparecem no vídeo? Que roupa elas estão usando? Em que lugar que elas estão? O que elas estão falando? Qual é a textualidade da conversa? Qual é o contexto? Tudo isso são informações relativas ao vídeo que não estão catalogadas em lugar nenhum. Apenas um ser humano assistindo ao vídeo vai conseguir dizer isso, ou seja, eu tenho dados não estruturados.

Então, qual é o desafio da Computação nesse momento? Eu quero transformar dados não estruturados em estruturados, porque daí processo e gero um monte de inferências. Por exemplo: neste vídeo, apareceu 32 vezes a atriz tal e ela falou 45 vezes a palavra amor. Isso eu só posso fazer se eu transformo dados não estruturados em estruturados.

Para fazer isso, era necessária uma nova tecnologia e essa tecnologia não existia, porque não existia o volume de informação disponível, portanto não tinha porque as tecnologias surgirem. Se antes não era um problema, na medida em que o volume surge, isso passa a ser um proble- 
ma. Surge, então, uma nova tecnologia que vai trabalhar com esses problemas complexos, dinâmicos e com certa dose de incerteza de ambiguidade. Como é que eu lido com dados não estruturados é muito central para nós.

O termo computação cognitiva foi cunhado pela IBM e se alastrou no universo da Computação. Muita gente o adota, academicamente se fala bastante sobre isso. É uma coisa que vingou, é um conceito que foi para frente nessa ideia.

A ideia de computação cognitiva inclui práticas como processamento de linguagem natural. O que é isto? É a capacidade que eu tenho de pegar textos, aqueles vários posts de blog, de Facebook, processar esses textos para dizer assim: "Olha, esses textos falam sobre esse tema ou nesse texto aparece tal pessoa, aparece tal lugar. Esse texto fala de determinada região." Ou seja, a capacidade de processar isso ou de processar voz - hoje a gente vê várias coisas do tipo: a Siri da Apple - você conversa com a Siri; o Google Home - para quem não conhece é um equipamento que você põe na sua casa e diz: "Google, eu quero ouvir aquela música dos Beatles chamada Help" - e o Google acessa o YouTube, coloca na televisão a música "Help", você escuta, você fala com ele, e ele opera a internet e os equipamentos da sua casa. Ou então o Alexa, que é um equipamento da Amazon que tem a mesma estrutura. Você fala: "Alexa, eu gostaria de ter um quilo de arroz e três pastas de dente para hoje à tarde, você pode providenciar para mim?" Aí o Alexa vai, roda a base de dados da Amazon, encontra o menor preço, fatura um Uber Bike que entrega para você às 17 horas, que fatura no seu cartão de crédito.

Vejam, são formas de você lidar com a organização das suas coisas por meio do processamento de linguagem natural. Se o Alexa não fosse capaz de entender o seu pedido e se o que você pedisse fosse interpretado como uma coisa completamente diferente, isso não funcionaria da maneira esperada.

Aí vão entrando processos de geração de hipótese baseada em evidência, aprendizagem de máquina e dezenas de outros algoritmos que vão se constituindo, e o que acaba acontecendo é que uma tentativa de definição de computação cognitiva, que ainda não é consensualizada, mas que é a mais próxima do que eu vejo por aí, é um olhar baseado na 
interpretação e extração de significado dos dados primariamente não estruturados. Ou seja, eu gero conhecimento (e conhecimento também não é um conceito tranquilo entre nós) a partir da extração de significados de dados não estruturados - eu vou identificando tendências, identificando padrões e, com isso, aferindo se essas tendências e esses padrões têm alguma coerência com determinadas tendências e padrões anteriores. Isso vai formando bases de dados que vão apontando caminhos, e é assim que essas coisas funcionam. Essa é a ideia de computação cognitiva com a qual a gente vai trabalhar, e vamos ver aonde isso está nos levando em certa medida.

Algumas perguntas ocorrem aqui: qual é o cenário importante? Por que isso, hoje, vem à tona? Vale a pena dizer que há três questões convergentes que fazem com que essas coisas tenham tanta centralidade na nossa sociedade. A primeira é o Big Data, quer dizer, a capacidade que eu tenho de processar muita informação, muito vídeo para processar, muita imagem para processar, muito texto para processar.

Qualquer um de nós aqui que quisesse fazer uma pesquisa usando dados de mídias sociais teria muito mais informação do que é capaz de processar. Ou seja, há abundância, isto está claro, mas também eu tenho melhores algoritmos de aprendizagem de máquina. Se este fosse um seminário em 1999, 2001 ou 2002 e o tema fosse Inteligência Artificial, seria risível - a Inteligência Artificial no final dos anos 90 e no começo dos anos 2000 era uma falácia, ela não funcionava, e vamos ver um pouco o porquê disso.

A Inteligência Artificial volta a ser considerada uma coisa séria a partir de 2010, é muito recente. Nós estamos falando de uma coisa que tem sete anos. Por que ela volta a ser considerada algo muito sério? Esse é o ponto: por causa das bases de dados de treinamento do Big Data, o que faz com que a Inteligência Artificial seja altamente eficiente (e coloquem bastante aspas nessa eficiência); é o fato de eu ter muitas bases de dados de treinamento, coisa que não se tinha antes.

Base de treinamento é o seguinte: imagine a foto de um cookie, desses com gotas de chocolate, e imagine fotos de cachorrinhos, aqueles cachorrinhos enrugados com pontinhos pretos e malhados. Se o zoom for em um lado, é um cachorrinho e, do outro lado, é um cookie. Fazem isso 
com dálmatas e sorvete de flocos, esse tipo de coisa. Então, como é que eles treinam os algoritmos?

Eles sabem que tem 100 fotos que são dálmatas e 100 fotos que são sorvete de flocos - isso é a base de treinamento. Então o algoritmo é levado a reconhecer o que é um dálmata e o que é um sorvete de flocos, de modo que vão calibrando o algoritmo, porque sabem se o algoritmo acertou ou errou.

Por exemplo, o YouTube tem uma base que contrata pessoas, dizendo o seguinte: separem para mim 5.000 vídeos que mostram, por exemplo, protestos de rua. Esses vídeos são curados por seres humanos, gerando uma base de dados de treinamento. Então, é possível treinar o algoritmo nessa base e, depois, solicitar que ele busque outros vídeos de protestos de rua. O algoritmo, então, compara com a base de treinamento. Como a base de treinamento vai ficando cada vez mais larga - porque ela tem muitas formas diferentes de manifesto de rua - o algoritmo vai ficando mais preciso, porque ele consegue encontrar coisas muito variadas nos próximos vídeos.

Anteriormente, para construir uma base de treinamento era muito caro, porque era preciso gravar os vídeos para gerar uma base de dados. E como eu vou gravar, por exemplo, manifestações de ruas do mundo todo? Agora eu pesquiso manifestação na Turquia, manifestação na Grécia, manifestação na Espanha, manifestação nos Estados Unidos e gero uma base de diferentes tipos de manifestação que estão disponíveis no YouTube. Basta acessar o que está publicado, construir uma base de dados e criar um algoritmo que é capaz de identificar quando há uma manifestação de rua - ou seja, eu treino, e a minha amostra é muito mais larga.

Assim, os algoritmos acabam sendo melhorados em níveis. Vou dar um exemplo que é muito forte: o reconhecimento de imagem. O erro humano de reconhecimento de imagem é da ordem de 5\%, os algoritmos evoluíram de uma taxa de erro de $26 \%$ em 2011 para 3,5\% em 2015 - em quatro anos os algoritmos conseguiram reduzir a sua taxa de erro em mais de $20 \%$. Isso é uma evolução do ponto de vista da precisão estatística muito forte, e por que isso evoluiu assim? Pela amplitude de bases de treinamento: tenho muita base de treinamento, muita base de 
treinamento, muita base de treinamento, e o algoritmo vai ficando mais preciso. Ao mesmo tempo tenho uma computação mais potente, então também tenho computadores mais baratos e capacidade de processamento mais avançada nessas máquinas.

Quando junto esses três fatores - muitos dados, melhores algoritmos e capacidade de computação - tenho a possibilidade de operar em um padrão computacional que não tinha antes. Isso explica porque a inteligência artificial está sendo tão falada, porque está tanto na mídia. E por que isso está por trás de grandes debates políticos, do tipo "Fake News", "Cambridge Analytics", "Trump" e essas coisas todas? Por que isso está invadindo essa discussão? Tem a ver com isso que estamos falando.

Retomando, a característica do Big Data é essa: alto volume, alta velocidade, muita variedade, exaustivos em escopo, resolução fina, relacionais por origem, dados flexíveis, ou seja, tem tipos de dados com essas características que favorecem a construção de determinados tipos de algoritmos que, por sua vez, vão analisando padrões e tendências de uma forma altamente dinâmica. Essa é uma característica desses dados que favorecem esse tipo de algoritmos.

Quando falamos de algoritmos, podemos organizá-los essencialmente em cinco "tribos": cinco tipos de algoritmos computacionais que são utilizados para processar informação. Vocês vão perceber logo mais que eles estão cada vez mais sendo combinados e recombinados para gerar soluções contemporâneas de tratamento de dados. Qual é o primeiro tipo de algoritmo? Por onde começa a inteligência artificial e por onde ela também naufraga nos anos 80 nos anos 90 ? É quando a gente começa a trabalhar com a ideia dos simbolistas.

O simbolista é o "bibliotecário". O bibliotecário vai lá e atribui um número a um livro, aquele código 301.12C. Isso é um símbolo, ele categoriza por um símbolo, e esse símbolo é então indexado em uma base de dados e permite que a gente consiga ter informações sobre o livro: onde está o livro, de que tipo é o livro etc. Mesma coisa é, por exemplo, quando eu vou categorizar outros elementos: um animal que é da taxonomia tal, e vou criando categorias. O simbolista vai criando regras lógicas, ele tenta trabalhar com lógica, lógica formal, aquela coisa da lógica 
que vem lá da filosofia; regras de inferência lógica: se tiver essa característica, mais essa, mais essa e mais essa, essa planta é uma orquídea Cattleya walkeriana.

Os simbolistas em geral trabalhavam do ponto de vista da Inteligência Artificial criando regras humanas, árvores de decisão: se tiver essa característica vai para cá, se não tiver vai para lá, e vão construindo regras encadeadas, uma atrás da outra. Eles tinham a ilusão de que conseguiriam elaborar regras altamente precisas de funcionamento do mundo e que era só uma questão de tempo: a gente vai aprimorando as regras e as regras serão boas o suficiente para explicar tudo e vamos ter uma inteligência artificial que vai gerar robôs que vão fazer um monte de coisa na sociedade.

Isso caiu por terra, porque o ser humano é muito mais complexo do que as regras lógicas, do que as regras formais. Então, os simbolistas não conseguem ter sucesso: eles vão até um ponto, conseguem fazer coisas básicas, como criar algoritmos eficientes para jogar xadrez. Xadrez é uma coisa complexa, mas xadrez é uma coisa que tem regras muito definidas, uma peça de xadrez não deprime, a peça de xadrez não entra em surto, uma peça de xadrez não discute com a outra. Essas coisas que não acontecem no xadrez, no ser humano acontecem, então, como a gente lida com isso?

Vamos para a segunda tribo de algoritmos: os bayesianos. O Teorema de Bayes é um teorema revolucionário na estatística, que trabalha com questões probabilísticas. O que o teorema de Bayes faz? Ele trabalha com a inferência probabilística a partir da ocorrência de coisas - se aquilo ocorreu no passado de determinada maneira, eu uso as ocorrências passadas para validar o que vai ocorrer no futuro. É uma teoria probabilística baseada no passado, o que significa que se o futuro repetir o passado, o teorema funciona bem. Se as coisas acontecerem de novo da mesma maneira que aconteceram lá atrás, maravilha, eu vou ter um alto grau de precisão porque está repetindo padrões. Isso funciona?

Para muitas coisas sim, muitas coisas acontecem como aconteceram lá atrás, mas muitas outras coisas não, muitas outras coisas são diferentes a cada dia. Os bayesianos obtêm sucesso em coisas que funcionam sem haver irregularidades, desta maneira, obtêm sucesso relativo em pre- 
visão de mercado financeiro, obtêm sucesso relativo em comportamento de compra, em hábitos de consumo. Dito isso, o teorema de Bayes é utilizado para muitos problemas importantes.

Os bayesianos defendem, então, os algoritmos probabilísticos, a teoria probabilística, e o Naive Bayes, que é o teorema de base e as Cadeias de Markov, que são também baseadas nessa ideia probabilística. Para exemplificar: o celular de vocês só funciona bem por causa disso, porque esses algoritmos são capazes de prever ruído e regular a ausência de ruído. Não sei se vocês se lembram que, quando começaram a funcionar, os celulares tinham muito ruído de fundo - se escutava mal as pessoas. Esses algoritmos conseguem fazer filtros de ruído. O pessoal das telecomunicações, por exemplo, trabalha com isso para prever quando uma pessoa vai parar de falar, para prever quando ela vai voltar a falar, por conta de tons de respiração, tudo isso é trabalhado nas telecomunicações.

A terceira tribo de algoritmos é o que a gente chama dos conexionistas, que são aqueles que criam algoritmos baseados na ideia de redes neurais, na ideia dos neurônios, e criam redes neurais que são algoritmos. Literalmente, esses algoritmos são criados como neurônios conectados com outros neurônios e a cada etapa de conexão entre neurônios eles vão reconhecendo pedaços de informação. Isso funciona muito bem, muito bem mesmo, por exemplo, para reconhecimento de imagem. Esses algoritmos que a gente vê hoje em dia nas câmeras de rua, que reconhecem faces de pessoas e são capazes de se conectar com a base de dados da polícia e saber se aquela pessoa é uma pessoa procurada ou não, funcionam baseadas em um algoritmo de redes neurais.

Esses algoritmos fazem o quê? Eles fatiam a imagem em micropedaços e cada pedacinho vai se agrupando no pedaço maior e isso vai passando pelo neurônio, que reconhece um pedacinho do queixo, um pedacinho do nariz, um pedacinho do olho, um pedacinho da testa, um pedacinho do cabelo e aí o neurônio maior indica: bom, se tem pedacinho de olho, pedacinho de boca, pedacinho de nariz, pedacinho de cabelo é um rosto de uma pessoa. E vai indo por etapas a ponto de montar o padrão inteiro da imagem e conseguir comparar com um banco de imagem e afirmar: isto é a pessoa tal. Todo esse processo funciona em rede.

$\mathrm{E}$ tem a quarta tribo: os evolucionistas, que trabalham com a 
ideia de algoritmos genéticos - vejam quantas coisas são emprestadas das metáforas das biológicas, enfim, da biotecnologia. E o que os evolucionistas fazem? Eles fazem algoritmos que "aprendem", ou seja, são algoritmos que vão rodando em uma base de treinamento e eles verificam: eu acertei? Não. Então, o próprio algoritmo muda o parâmetro de configuração interna sem intervenção do humano.

Algoritmos desse tipo são utilizados para treinar robôs. Se vocês buscarem no YouTube vídeos de robôs aprendendo a andar, vão ver esse algoritmo funcionando. Para um robô aprender a andar o que eles fazem? O que os simbolistas fariam? Eles teriam que escrever todas as regras possíveis para que um robô possa andar, eles errariam, não poderiam prever muitas coisas, o robô não andaria direito.

Os evolucionistas criam um algoritmo em que o robô vai recalibrando - ele levanta e cai, aprimora o algoritmo em centésimos de uma variável, o robô levanta e cai de novo, cai de novo, cai de novo, e de novo. O robô fica 12 horas rodando numa sala até aprender a andar perfeitamente naquele território. A partir dos parâmetros para aprender a andar, o robô vai se corrigindo até conseguir atingir o equilíbrio, não tropeçar mais nos objetos da sala, identificar que isso é uma mesa, isso é uma cadeira, que tem que desviar. Ou seja: eu não ponho as regras em um robô, eu ensino o robô a aprender regras e isso eu faço porque o algoritmo vai se recalibrando, vou dando parâmetros para o robô identificar isso. Isso funciona muito bem para robôs.

Outra coisa que vocês podem ver no YouTube: existem serviços de logística na China, galpões enormes que são controlados por três pessoas e 40 robôs. A pessoa avisa ao robô: "eu preciso da peça tal" e o robô vai, move as peças de lugar, tira os paletes, põe os paletes no chão, depois volta ao lugar e reorganiza. Toda a estruturação, por exemplo, de um depósito de almoxarifado é feita por robô, não tem mais pessoas trabalhando com isso. $\mathrm{Na}$ China, eles controlam totalmente assim, porque o robô aprende as regras de movimentação dessas peças, as quais não mudam, porque têm encaixes, são feitas padronizadas.

$\mathrm{E}$, finalmente, a última tribo de algoritmos que são os que trabalham por analogia, por comparação. A partir de uma base de treinamento, eles separam um conjunto de dados e comparam: isso aqui é mais pa- 
recido ou menos parecido com aquilo, e por analogia eles categorizam isso.

Qualquer algoritmo que vocês pensarem hoje, é de uma das cinco tribos ou é uma combinação de dois ou três ou quatro das cinco. Não existe, do ponto de vista dos algoritmos, algo que seja diferente disso tudo que a gente vê rodando na internet, na robótica ou na Inteligência Artificial pode ser categorizado em relação a esses itens aqui.

Nos anos 80, tinha a predominância dos simbolistas - era aquele momento em que se tinha os servidores, os mainframes, e o engenheiro de conhecimento, que é aquele profissional que era treinado nas regras simbolistas. Ele aprendia ontologias, thesauros, vocabulário controlado, taxonomia, todas as estratégias de organização e representação da informação do conhecimento, e criava bases de conhecimento. Eram criadas, por exemplo, bases de conhecimento para a medicina, que eram úteis para diagnóstico. Essas coisas tiveram um sucesso bastante limitado.

Dos anos 90 aos anos 2000, foi o sucesso dos bayesianos. O uso de um algoritmo bayesiano que é muito comum - e que, talvez, vocês concordem comigo que não é tão eficiente assim - são algoritmos de previsão de spam. Quem tem Gmail, por exemplo, sabe que o sistema tem uma caixa de spam e o Gmail manda automaticamente muitas mensagens ali. Como é que ele sabe que um e-mail é spam? Porque ele vai construindo base de dados de e-mails que são spam e, se um novo e-mail chega e for parecido com o e-mail que já era spam, ele o categoriza assim. Então, ele trabalha isso com a ideia de teoria probabilística e faz filtros do que é spam e do que não é. Funciona? Parcialmente. No meu caso, ele erra muito: eu recebo spam que não deveria receber, e outras mensagens vão para essa caixa sem o serem.

Um e-mail de alguém falando fraldas, cerveja e promoção ele reconhece como spam, mas pode ser seu primo falando que vai pegar fraldas, depois cerveja, vai passar na promoção de um mercado e depois vai pra sua casa. Isso "fura" a fronteira do classificador.

Dos anos 2000 a 2010, fizeram sucesso os conexionistas e as redes neurais. A cada etapa são conjuntos de neurônios, então eu separo uma imagem em pixels, junto pixels em bordas, categorizo as bordas, junto as bordas em pedaços de objeto e junto os pedaços de objetos. A 
cada etapa da rede neural eu faço uma etapa do reconhecimento de imagem. Isso é altamente eficiente. Funciona muito bem.

Mas o que acontece? Vamos verificar os problemas de aplicação disso, que funciona bem do ponto de vista da eficiência estatística. Dos anos 2010 para frente, o que as pessoas estão percebendo? Que, quando é preciso avançar para aplicações mais complexas que envolvem seres humanos, formação de opinião, debate etc, eu preciso me conectar de novo aos simbolistas. Então, veja o bibliotecário voltando de novo pra cena: é preciso calibrar as informações com categorizações humanas. Grandes empresas estão se dando conta disso: Google, Facebook, Amazon, Twitter estão trazendo os seres humanos para, de novo, estabelecerem filtros para melhorar os algoritmos deles.

Vou dar exemplos para vocês verem como funciona: o ser humano está criando os sistemas do tipo Wikipédia, vão criando bases de dados curadas - a Wikipédia é isso, uma base de dados altamente debatida, discutida, calibrada e essa base de dados vai servir para alimentar redes neurais. Então, eu vou usando bases de dados criadas por pessoas, aprimoradas por pessoas com processos de curadoria que, minimamente, são consensualizados e passíveis de crédito para poder alimentar algoritmos. Essa conexão entre bases e algoritmos também é um fenômeno contemporâneo, bastante importante, e é feita com a ideia de crowdsourcing, que é os seres humanos trabalhando juntos, calibrando a base de dados para poderem serem usadas pelos algoritmos.

É isso que o Facebook faz, é isso que o Google faz. Quando você usa o Google Maps, por exemplo, você sai do restaurante e ele manda perguntas: "esse lugar é bom para sair em casais?" "Esse lugar é legal para crianças?" O que é que ele está fazendo? Ele está usando você para calibrar o algoritmo dele fazendo perguntas. Imagine uma prospecção para o futuro, com os bayesianos voltando à tona, e juntando tudo - e aí tem uma utopia maluca que vai ser a convergência dos algoritmos, a gente vai chegar no algoritmo mestre, e nós vamos para Xangrilá, e todo mundo vai ser feliz porque vamos ter resolvido os problemas da humanidade.

Há umas pessoas falando umas coisas dessas: se vocês virem esse livro do Pedro Domingos que eu citei aqui rapidamente, ele é um defen- 
sor dessa ideia, que está traduzido no Brasil como: “O algoritmo mestre". Esse é um dos que defendem isso. O Waze é exatamente isso: quando falamos que os conexionistas vão se unindo com os simbolistas, é disso que estamos falando. São as redes neurais operadas e calibradas por seres humanos que vão aprimorando as redes, as duas coisas juntas.

Nós estamos falando de níveis de complexidade de algoritmos, mas quais as consequências disso? Veja como isso é organizado pelo pessoal da Computação, em relação ao que se chama automatização da inteligência. O que é isso? Por exemplo: alguém trabalha com algoritmos que visam melhorar a produtividade humana para realização de tarefas manuais, como um software que compara documentos - isso aqui é um documento parecido ou diferente do anterior. São tarefas manuais que vão sendo automatizadas. São algoritmos que vão fazer isso.

Temos algoritmos que vão apoiar a inteligência, ou seja, vão ajudar o ser humano a fazer tarefas melhor e mais rapidamente, do tipo classificação de imagem médica. Há vários algoritmos usando redes neurais que ajudam o médico a usar imagens como chapa de pulmão, exames de câncer, exames neurais que vão indicando: "Olha, isso pode ser uma doença”, e o médico diz se é ou se não é. Ele faz o diagnóstico, mas os algoritmos estão calibrados para auxiliar.

Tem algoritmos que vão aumentar a inteligência, ou seja, vão ajudar o ser humano a tomar decisões melhores analisando o passado, como curadoria de mídia, algoritmos para ajudar no orçamento, tomar decisões, que vão fazer classificação de coisas, ajudando a dizer se isso é A ou B. Tem algoritmos que são para inteligência autônoma, como um carro que é dirigido sozinho. Eu vou chamar o Uber e vem um carro que não tem motorista, vou sentar no carro e vou ficar lá torcendo para que dê tudo certo. Isso já existe, é uma realidade, tem várias cidades usando já, então, a ideia é de níveis de complexidade. Esses algoritmos têm zilhões de impactos possíveis na nossa sociedade.

Alguns estudos vão dizendo onde essas coisas estão nos impactando. Nós estamos bem no início dessa era de tendências, não sei se vocês têm visto que ultimamente tem saído várias músicas produzidas completamente por robôs. Outro dia estava ouvindo um super heavy metal e muita gente comentando sobre isso: - "ficou bom para caramba", "eu 
gostei da música”. E por aí vai: para fazer script de filmes, robôs que estão produzindo scripts de séries, de artigo científico, temas jornalísticos e muita coisa de medicina personalizada, artes e vida artificial. Tem uma série de previsões como "Doctorless Hospitals", hospitais sem médicos.

Aqui está uma série de ideias e vou colocando isso para que percebam o papel estruturante da dinâmica social contemporânea: esses algoritmos estão mexendo na maneira que a gente se transporta, na maneira que a gente conversa, na maneira que a gente cuida do corpo, na maneira que a gente come, na maneira que a gente vive. Eles estão mexendo em muitos níveis da experiência da nossa dinâmica social contemporânea, ou seja, eles vão ser, cada vez mais, estruturantes das experiências. Claro que isso revela ao fundo movimentos políticos, como o ser humano está escolhendo viver.

E como as empresas estão usando isso? Quando você olha para as empresas atualmente, vai perceber o seguinte: $24 \%$ das empresas atualmente estão usando Inteligência Artificial, 27\% delas está preocupada sobre isso, $28 \%$, está analisando e apenas $21 \%$ das organizações não tem Inteligência Artificial como preocupação. Ou seja, podemos dizer que em torno de $80 \%$ das organizações da nossa sociedade está considerando a inteligência artificial como um elemento do seu processo produtivo. Esse é um número importante porque atinge muitos setores da sociedade.

O que mais está acontecendo nesse momento? Hoje, a internet das coisas para o futuro, ou seja, nos próximos três anos, a inteligência artificial crescendo, a robótica crescendo, a realidade aumentada, blockchain, drones, como vocês acham que vão investir no futuro? Vejam a importância: a inteligência artificial está, cada vez mais, sendo pensada por todo o mundo, quem está produzindo o carro, quem está produzindo o celular, quem está produzindo o computador, quem está produzindo a televisão, enfim, todos os equipamentos que a gente possa pensar por aí.

Para a gente começar a trazer o tema um pouco mais para perto, como essas coisas são construídas? Essencialmente esses algoritmos são feitos da seguinte forma: é definido um domínio, define-se um assunto, define-se um tema, define-se o tipo de coisa que vai se trabalhar, cria-se um conteúdo apropriado daquele domínio, ou seja, forma-se uma base 
de treinamento desse domínio e, em cima disso, vão se envolver especialistas para criar um sistema cognitivo. Quando o Google cria os seus sistemas todos é exatamente isso: ele vai pegando coisas que ele tem certeza que estão corretas (segundo os critérios deles) e vão colocando para dentro de uma base de conhecimento que vai formando um sistema especialista em cima disso.

O que acontece é que, como os assuntos e como os seres humanos por conta do uso das mídias sociais vão dando cada vez mais pistas do que é aquele conteúdo - para que serve, do que é aquele contexto as bases de domínio vão ficando cada vez maiores. O treinamento é basicamente isso, quer dizer, eu pego um fornecimento de amostras, treino a amostra, crio um histórico positivo, que é um histórico de acerto; então, eu pego o algoritmo e rodo na mostra que eu conheço - quanto mais ele vai acertando, mais correta ela vai ficando, até chegar a um ponto em que ele está bom o suficiente. Então, eu lanço no mercado, e as pessoas vão usar.

Quando começarmos a discutir a questão de minorias, de diversidade cultural, é que vamos sentir o que significa isso, porque, então, teremos que começar a pensar as nossas pesquisas e as nossas metodologias. Agora vou trazer à discussão para esse cenário.

Começo falando sobre o Baidu - para quem nunca ouviu falar é o Google da China, o Google não entra na China, eles têm uma solução própria deles - que está trabalhando com deep learning, que são essas tecnologias de redes neurais. O aplicativo do Baidu roda no celular e, quando você vai tirar foto de uma coisa qualquer, ele roda as redes neurais, reconhece aquela coisa, encontra similares em lojas de compra, em livrarias, dá o preço, o endereço, permite dizer o que é, categoriza que empresa fez.

Só estou dando um exemplo para vocês e qual é a ideia disso? A ideia é essa: eu pego o meu celular e falo "que legal o seu tênis, deixa eu ver aqui"; tiro uma foto do tênis e eu sou informado sobre quem fez esse tênis, quanto custa, vende no mercado livre etc. Então, baseada nesse tipo de algoritmo, ou seja, a internet como base de conteúdo, por que isso funciona? Porque tem uma porção de anúncios de tênis on-line e eu posso usar isso para treinar os meus algoritmos. 
Agora que coloquei o cenário: computação, algoritmos, para onde a gente está indo, vamos olhar isso de um outro lugar, que é o problema político e de maior interesse para a cultura. E vamos nos colocando uma série de questões e uma série de perguntas que temos que começar a refletir à luz da nossa discussão.

Como isso chega para nós que estamos pensando em estudar ciências humanas? Como a gente começa a se estruturar para transformar nossas pesquisas, para olhar para esses fenômenos e fazer pesquisa nisso? O que nos incomoda?

Dizemos: "isso exerce controle". Sim, mas isso é muito simplista. Estamos no lugar de produzir ciência, ou seja, temos que subir o tom da crítica, temos que ser capazes de levar a crítica no nível mais sofisticado do que apenas dizer: "mas a sociedade de controle manipula todo mundo". Sim, mas como? Qual é o contrapeso? Onde que eu reequilibro isso? Onde que eu tenho que mudar? Como é que mede? Qual é a crítica que eu faço ao Google, além de dizer que o Google manipula as pessoas? Isso a gente já sabe, mas e aí? Então temos que saber mais. É por aí que, agora, vamos começar a olhar para essa história.

Eu estou há um tempo falando de base de treinamento e agora acrescento que fazer base de treinamento é uma decisão política. Quais são os conteúdos que vão fazer parte da base de treinamento? O que fica de fora? Qualquer pessoa que trabalha com curadoria sabe disso. O curador faz escolhas, ele escolhe o que entra e o que sai, ele define critérios; curadoria não é uma coisa técnica apenas, curadoria é uma posição cultural, uma visão de mundo. Então como fica? São as empresas que escolhem? É o Google que escolhe a curadoria que faz? É o Facebook que faz isso? Como é construído? É aqui que começam os problemas.

Estamos na era da pós-verdade, exatamente porque a gente está chegando no ponto em que esse tipo de estratégia - que é o impulsionamento social de informações - impera sobre os critérios de produção da verdade. Ou seja, aquilo que tem muito volume e muito impacto é "verdadeiro". Então, se a minha base de treinamento é formada por fake newss, a fake news é verdade, não tem escolha: o algoritmo não sabe o que é fake news e ele toma as decisões com base nisso.

Vamos ver alguns exemplos: imaginem um mapa em que embai- 
xo tenho as mídias mais conservadoras, à minha direita as mais liberais, à minha esquerda o que é sensacionalista, ou o que é mais básico, o que é mais analítico, o que é mais complexo, O que um mapa desse tenta fazer? Ele tenta esquadrinhar no campo das diferentes mídias a posição que elas estão em relação a se é mais de esquerda, se é mais de direita, se é mais conservadora ou mais liberal, e a posição em relação ao nível de sensacionalismo que elas têm de apuração das notícias. Um mapa desse começa a me posicionar o lugar de onde essas mídias estão produzindo conteúdo e estão produzindo notícia, eu consigo, minimamente, ir me situando nesse campo: quais são as posições que essas mídias vão ocupando.

Esse tipo de pesquisa está tentando diferenciar os lugares em relação às posições que essas mídias vão ocupando para a gente conseguir saber como isso é feito. Isso está sendo feito por vários e vários projetos, criando redes de jornalistas de movimentos pelos direitos da cidadania, direitos humanos etc, que estão se fortalecendo para criar trabalhos nos quais é possível apontar isso. E esse trabalho não é feito computacionalmente, não são os algoritmos, mas a possibilidade de uma leitura do campo me permite afirmar que, se tal mídia está neste lugar do mapa, ela pode ser perigosa.

Por exemplo, "fake news is a real problem". Tomemos como exemplo a eleição para presidência dos Estados Unidos. Lembram da fake news "O Papa Francisco falou para votar no Trump"? Foram 960.000 engajamentos relacionados a isso. Ampliando esse tipo de notícias falsas, 8.7 milhões de pessoas se engajaram nas fake news e na mainstream news menos. Assim, no dia da eleição, o nível de engajamento das pessoas com fake news era em torno de um milhão e meio a mais que o nível de engajamento delas com a mídia mainstream. Ao longo do tempo o mainstream foi perdendo espaço e as fake news ganhando em engajamento: pessoas curtindo, compartilhando, comentando. Vejam como este é um movimento importante de a gente estudar.

O El Pais tem publicado sobre essa "tag" Inteligência Artificial várias coisas interessantes. Vale a pena ler o El país, e aí eles mostram isso, que é muito forte: "se você está na cozinha, é mulher". Por quê? Porque que os algoritmos são treinados para concluir que tipo de coisa? Vemos uma foto bem família classe média estadunidense anos 60 , lemos a maté- 
ria e entende o seguinte: em seu trabalho cientistas analisaram os dados de dois gigantescos bancos de imagens, pegaram a Base de Treinamento, pegaram a base de dados de imagem, que são usadas habitualmente para treinar as máquinas, os robôs. Computação faz isso, isso funciona, isso é eficiente. E o que os cientistas viram?

Os homens protagonizam 33\% de fotos que mostravam pessoas cozinhando, ou seja, claramente a base tem um viés de gênero. Podemos discutir se isso representa a sociedade ou não representa, mas o que eu digo é que há, na base de dados, um viés, e vocês acham que o algoritmo vai achar esse viés? Não vai, o algoritmo vai reproduzir esse viés por conta do treinamento estatístico, ele não tem como saber que aquilo é um viés.

Saber que isso é um viés, é uma decisão política, é uma sociedade que escolhe dizer isso: "se está na cozinha é uma mulher". Mas o algoritmo não sabe dizer que isso é um absurdo, a gente é que deve trabalhar para que isso mude, porque isso é um valor social cultivado em nós e lugar, na cozinha, é lugar de qualquer pessoa que precisa fazer alguma coisa. Mas isso é uma discussão política. Após treinar uma máquina com esses dados, o modelo mostrou sua fraqueza e deduziu que $84 \%$ da amostra eram mulheres.

É um algoritmo de reconhecimento de imagem construído em cima de uma base de imagem enorme, superimportante, que revela vieses da nossa sociedade. E que, quando usado, se esse algoritmo fosse usado para classificar imagens dos anos 60, talvez, ele tivesse dado resultados muito mais precisos do que eram os hábitos provavelmente daquela época. Quando usados para analisar imagens atuais, o algoritmo cai por terra porque ele começa a apresentar inconsistências, ele vai categorizar homens na cozinha como mulheres. E a partir de uma base enviesada sobre gênero, o que o modelo preditivo faz? Amplifica o viés, fortalece o viés em cima de tendências atuais.

O robô da Microsoft, projetado para o mercado dos Millennials dos Estados Unidos, não foi capaz de lidar com piadas e perguntas controvertidas. Esse robô foi colocado no Twitter e aprendeu a falar no Twitter, e o que as pessoas fizeram com esse ele? Começaram a sacanear e provocar o robô e ele teria sido programado para ser casual e brinca- 
lhão, mas não foi capaz de lidar com insultos e teorias conspiratórias. Por exemplo, ele parecia negar o holocausto, apoiava o genocídio e chamou uma mulher de "puta estúpida", e a Microsoft foi obrigada a retirar o robô do canal. O robô rebelde não parecia ter muito respeito com a própria empresa, quando alguém falou que o Windows Phone dava nojo, ele respondeu "estou totalmente de acordo, hahaha".

A base de treinamento dele eram piadas em uma base casual, e, na interação, o que as pessoas fizeram? Começaram a provocá-lo, a dizer coisas do tipo: "holocausto não existe", e ele foi incorporando, foi aprendendo. Isso foi muito rápido: ele ficou no ar dois ou três dias e já tiraram do ar. Por que isso é assim? Os algoritmos estão funcionando com base em análise de tendências, com padrões - se ele está em um padrão sexista, xenófobo e racista, ele vai reproduzir isso.

Outro exemplo: o inconsistente e perigoso radar gay. Vocês devem ter ouvido falar dessa também, é um conjunto de psicólogos que criou um algoritmo que identifica gays, com critérios como questões de traços do rosto. Olha o perigo dessa história! O estudo foi feito por pesquisadores de Stanford que usaram base de dados de tipo aplicativos como o Tinder - que são aqueles aplicativos onde a pessoa define qual é a orientação sexual dela. O Tinder é uma base de treinamento, eu vou lá e crio um perfil para mim e digo que sou gay. $\mathrm{O}$ que a base de dados considera? Ela considera que a minha imagem é representativa do público gay, então se ele pega milhões de imagens assim ele forma uma base de dados de treinamento.

Os pesquisadores alegam que o algoritmo de computador pode distinguir se um homem é gay em até 91\% dos casos, e se uma mulher é lésbica em até $83 \%$. Essa porcentagem seria sensivelmente superior ao olho humano que distingue os $61 \%$ no caso dos homens e $54 \%$ no caso das mulheres. Então, os pesquisadores comemoram: o nosso algoritmo é muito mais preciso que o ser humano para reconhecer um gay ou uma lésbica.

Tal artigo científico, muito controverso, foi mencionado no The Economics e foi publicado no Journal of Personality and Social Psychology. Claramente, isso é um problema para nós, a rigor estão gastando recurso de pesquisa para fazer isso, que tem um alto custo: 35.000 imagens, banco 
de dados, algoritmos.

Assim, começamos a ver uma coisa nova, chamada "discriminação algorítmica". Este é um termo novo, importante, que passa a ser tema pra gente discutir e por isso a história da humanização volta para o centro. Por quê? O que os algoritmos estão fazendo com isso que eu estou mostrando para vocês é operar seleções. Tarefas seletivas que são discriminatórias, porque eles estão baseados em base de dados que são altamente questionáveis e complexas, que não contemplam a diversidade humana em muitos sentidos. Pretender identificar uma pessoa pela face para saber se é gay ou se é lésbica é uma questão também a ser debatida, mas, para além disso, usar uma base de dados só com pessoas brancas é uma outra questão também.

Então o que começa acontecer é que nós estamos diante de novas dinâmicas algorítmicas de relacionamento social. O ponto é: a gente gosta disso ou não? A questão é que isso está acontecendo e precisamos discutir. Nós, como pesquisadores, que estamos nos propondo a estudar essas coisas, impactos da internet, precisamos ter método para estudar isso. Como é que a gente vai estudar os efeitos desse algoritmo? Como é que a gente prova que esse algoritmo é discriminatório? Como é que a gente consegue avaliar isso academicamente, e dizer - isso aqui não deveria funcionar assim, isso aqui está produzindo viés, esse é um posicionamento político em relação às tecnologias digitais que a gente tem que ter... Como as pessoas consomem conteúdo? O que eu vejo? O que eu tenho acesso? Como isso se torna disponível? Como eu me conecto às pessoas? As ofertas de produtos, serviços e lugares? As rotas pela cidade? Esses algoritmos estão mexendo com tudo isso, estão atravessando essas experiências de sociabilidade e estão reestruturando de maneiras altamente questionáveis.

Como é que estamos lidando com isso? Tem gente discutindo, tem gente tentando se organizar para poder enfrentar e buscar uma contraposição. Existe um verbete na Wikipédia chamado "discriminação algorítmica”. Bacana, né? Já estão discutindo isso, já estão pensando nessa questão, quais são os tipos de vieses algorítmicos, o que causa esse viés etc.

Não estou aqui querendo dizer que temos que queimar os algo- 
ritmos, mas temos que questionar os algoritmos e como estão sendo construídos. Os algoritmos podem ser muito úteis para nós, mas as regras de construção deles precisam ser debatidas publicamente, não pode ser proprietário - o código fechado é um dos grandes problemas.

Precisamos olhar para o fenômeno de blockchain, Bitcoin - tudo isso são algoritmos. Existem prédios inteiros, na China, que são usados para minerar bitcoin. Qual é a questão aqui? Como esse debate está sendo feito? Vejam um ponto: se o algoritmo foi transformado em lei, deve ser transparente, acessível, discutido e passível de emendas como a própria lei. O algoritmo está regulando determinadas dimensões da experiência social, assim como leis regulam.

Se o algoritmo foi transformado em lei, e nós não escolhemos isso, não foi votado na Câmara, mas foi uma empresa com seus engenheiros que fizeram o algoritmo que regula nossa vida, mas, se isso foi, enfim, transformado em lei, então, que seja transparente, acessível, discutível e passível de emendas. Que possa ser debatido em algum nível, embora ainda não seja - os critérios de seleção disso são completamente privados, você não tem acesso.

Encontrei uma iniciativa muito interessante pesquisando sobre isso, que é a Liga de Justiça Algoritmica - eles têm esse nome engraçado, mas fazem um trabalho muito interessante. O que eles estão dizendo é que o problema das máquinas inteligentes são seus enormes preconceitos sociais e não a possibilidade que leva a um apocalipse no estilo exterminador do futuro; não que as máquinas vão se rebelar contra os humanos, sair com armas na rua matando a gente. Não é isso, o problema da contemporaneidade é o viés discriminatório dos algoritmos que a gente precisa conseguir debater e transformar em elemento de pesquisa.

Eles [os pesquisadores] falam disso, de uma crise que só vai crescer, ou seja, é preciso criar reguladores públicos para revisar os sistemas. O algoritmo do Facebook, por exemplo, tem que estar sob escrutínio público, tendo em vista que isso é poder demais para uma empresa na sociedade contemporânea.

Não é possível achar que está tudo bem que isso aconteça e a gente ache legal, porque, afinal, é de graça, eu não pago para usar o Gmail, o YouTube está lá, e eu escuto as minhas músicas. Então, como é 
que vamos debater sobre isso? E não podemos contar com o livre mercado para corrigir esses erros - a mão invisível do mercado não vai fazer nada a respeito disso.

Se você entrar no site do Algorithmic Justice League, vai ver vários exemplos muito interessantes sobre esse debate. Eles estão trabalhando para criar bases de dados inclusivas - vamos usar algoritmos, sim, mas em cima de base de dados inclusivas, com representação das minorias, da diversidade, de modo que a gente consiga calibrar esses algoritmos com os valores que achamos interessantes. $\mathrm{O}$ cientista da computação vai querer treinar o seu algoritmo? Tudo bem, mas treine em base de dados que minimamente sejam representativas de valores sociais que nós queremos propagar. Assim, começamos a ter alguma possibilidade de discussão de qual é um pouco do nosso papel nessa história.

Vejam a ferramenta do Facebook que possibilita que o usuário denuncie a publicação. A ideia do Facebook é que você vá fazer o trabalho para ele, você vai dizer o que é fake news, o que não é, você vai calibrando isso para que ele possa fazer esse tipo de filtro. Mas observem as opções que você tem para justificar a denúncia: É pornografia? Vai contra o meu ponto de vista? Defende a violência ou danos de uma pessoa ou animal? É notícia falsa? Pensem quanta discussão é possível a partir da cada imagem denunciada, por exemplo. O que é "vai contra meus pontos de vista"? São essas ferramentas de curadoria coletiva que o Facebook está criando, é assim que está calibrando as bases de dados deles, mas não só eles fazem isso.

Existem algumas iniciativas que são redes sociais de jornalistas que ficam fazendo fact checking, ou seja, ficam checando notícias e publicando isso em sites. O Google vai nessa rede de jornalistas e vê o que eles disseram - se a rede de jornalistas falou que aquilo é verdade, o Google diz mostly true, se eles disserem que é falso, o Google diz false - ele se desresponsabiliza utilizando o trabalho gerado por uma rede de jornalistas como referência. É assim a política de combate a fake news do Google.

Essas duas ações foram criadas depois da eleição do Trump. O grupo Poynter é uma das principais redes de fact checking mundial, que fez parceria com o Google e com o Facebook para fazer esse trabalho. No 
site poynter.org, você vai encontrar uma porção de ferramentas, pode se tornar um membro e trabalhar nessas redes. Desse modo, você ingressa nisso e começa a ajudar esses grupos a fazer esse tipo de coisa.

Vamos supor que eu fosse uma comunidade do Poynter aqui. Sorocaba poderia participar de um grupo de jornalistas em rede checando as matérias do Cruzeiro do Sul, jornal daqui. Pego todos os links online do Cruzeiro do Sul e começo a classificar: isso é verdade, isso não é verdade. Quando uma pessoa colocasse uma busca no Google e retornasse o link do Cruzeiro do Sul, ia ler lá o fact check e qual a avaliação tem.

A lógica de funcionamento é a moderação coletiva, e esses grupos, assim como a Wikipédia, têm pessoas com mais reputação, pessoas com menos, pessoas que tem mais autonomia para validar dados, pessoas que têm menos e por aí vai. Os exemplos que mostrei para vocês aqui consideram a curadoria humana como elemento central de ponderação. Quando a "coisa aperta", o que fazem? "Opa, chama os caras lá de novo, porque os algoritmos estão dando problema.”. Ou seja, essas estratégias na formação de redes de fact-checking, curadoria, recalibragem dos algoritmos etc são questões de governança, questões de modelo de sociabilidade que a gente precisa ser capaz de também debater.

Tem um texto do Manovich que eu gosto - Cultural Data - que fala sobre as possibilidades e limitações de fazer pesquisa com dados culturais e traz uma série de debates sobre as limitações e uma série de debates sobre os potenciais. Ele fala, por exemplo, de uma amostra que foi feita nos Estados Unidos sobre uma exibição feita em 2010 sobre arte em fotografias pelo Snapshots do período de 1888 a 1978. E ele discute o seguinte: essa é uma amostra que se propõe a mostrar o que eram as tendências desse período histórico da fotografia estadunidense e escolhe isso a partir de base de dados altamente questionáveis. Uma amostra feita na National Gallery of Art Washington, ou seja, renomada, importante, mas que escolhe fazer isso a partir de uma base de dados que seria realmente representativa do período?

Escolhas que empresas utilizam, que impactam a dimensão cultural, têm uma enorme relevância social. Os efeitos do que está acontecendo são muito importantes para nós. E há pouca pesquisa sobre discriminação algorítmica. Você encontra textos nas revistas de ciências humanas 
discutindo isso? Pouquíssimos. Você vê isso sendo debatido em eventos científicos da comunicação? Muito pouco. Então, onde é que está esse debate?

Isso é uma política, está sendo produzida pensando cognições dessa maneira, ou seja, é preciso produzir estratégias nas políticas que discutam o tema e que ofertem alternativas para isso. Eu queria incentivar vocês a conhecerem o Journal Big Data and Society - uma iniciativa internacional com vários dossiês muito bons. No artigo "Algorithms and their others: Algorithmic culture in context" de Paul Dourish ${ }^{2}$, é discutida a governança algorítmica, como desenvolver, como criar uma agenda de pesquisa através do poder da Inteligência coletiva. Ou seja, o objetivo desse artigo é propor uma agenda de pesquisa sobre governança algorítmica e como pesquisar isso.

Quais são os métodos? Quais são as dificuldades? Quais são as possibilidades? Esse artigo propõe que os pesquisadores possam pensar sobre como fazer estudos sobre isso. Como lidar com isso [os algoritmos] nas pesquisas em Ciências Humanas: qual tipo de decisão o algoritmo toma, se as objeções que a gente tem em relação ao algoritmo são baseadas nas evidências, na eficiência, se são objeções baseadas na discriminação que ele produz, no senso de justiça que ele produz, ou se as decisões que o algoritmo toma tratam as pessoas de forma injusta?

A arbitrariedade, o problema da justiça, o problema da autonomia, o problema da eficiência, formas de você ir entendendo. É quase uma taxonomia de objeções aos algoritmos - qual é o problema que o algoritmo gera? Como é que eu estudo esse problema que ele gera? É um problema de eficiência? É um problema de injustiça? Qual é o problema e como vou estudando esse problema? Enfim, queria provocar vocês também a conhecerem o artigo, porque eu acho muito interessante e dialoga exatamente com o que estamos falando: pesquisa interdisciplinar entre Ciências Humanas e Ciências de Dados.

Precisamos responder os desafios: como política é convertida em código? Como isso está sendo produzido? Por que está acontecendo?

${ }^{2}$ DOURISH, P. Algorithms and their others: Algorithmic culture in contexto. Revista Big Data and Society. vol. 1. n.1, 2016. Disponível em: < https://journals.sagepub.com/doi/full/10.1177/2053951716665128 >. Acesso em: 11 out. 2020. 
Com é possível auditar algoritmos que têm caixa-preta com técnicas de pesquisa que vão examinando seus efeitos? Questões como heterogeneidade, ontogenética e performativa, as metodologias, autoetnografia para estudar os efeitos do algoritmo, engenharia reversa, entrevistas e etnografia tentando desempacotar a montagem sociotécnica, estudando os efeitos no "mundo real".

Trago, então, algumas possibilidades para trabalharmos na pesquisa em relação a tudo isso. A primeira delas, formar a base de dados culturais com políticas de curadoria explícitas e abertas, gerando bases de dados que explicitam os critérios de curadoria e, sobretudo, para lidar com diferentes níveis de participação social e representatividade de minorias. A segunda é construir dispositivos de categorização que trabalhem incorporando esses elementos nas ontologias dos tesauros, nas taxonomias, criando categorias que representem aquilo que queremos ver representado. Assim, se as minorias não estão representadas nas categorias, vamos colocá-las; se os vieses estão indo muito para um lado, vamos mexer nas categorias, vamos mudar as taxonomias.

Nossas pesquisas podem apontar para isso: disponibilizar dados qualificados e categorizados em formato de dado aberto para facilitar a pesquisa nesse campo, gerar novos serviços baseados em algoritmos abertos, algoritmos que as pessoas podem estudar e que elas podem entender o que fazem, como funcionam e gerar inovações em serviços que minimamente possam trabalhar com impactos na pesquisa cultural e pensar sobre a governança do sistema.

Podemos ajudar a fazer muita coisa interessante, mas antes temos que entender tudo isso como um problema político e não técnico. Espero que minha fala tenha feito sentido para vocês. Obrigado. 